\title{
Why Would Social Networks Be Linked to Affect and Health Practices?
}

\author{
Sheldon Cohen \\ Carnegie Mellon University
}

\author{
Edward P. Lemay \\ Yale University
}

\begin{abstract}
Objective: To examine the relation among social integration (SI), affect, and smoking and alcohol consumption. Design: The authors administered social network and psychological questionnaires to 193 adults and then interviewed them on 14 consecutive evenings about their daily social interactions, affect, and smoking and alcohol consumption. Main outcome measures: The main outcome measures were positive and negative affect, smoking, and alcohol consumption. Results: Between-subjects analyses found that those with more diverse social networks (high in SI) interacted with more people and smoked and drank less. SI was not, however, associated with affect. In contrast, within-subject analyses found that the more people participants interacted with during a day, the greater their positive affect, drinking, and smoking on that day. However, this occurred primarily for persons low in SI. High-SI persons reported high positive affect irrespective of the number of people with whom they interacted, and their smoking and drinking behaviors were less influenced by number of interactants. Conclusion: SI may alter health because it affects responsiveness to the social influences of others.
\end{abstract}

Keywords: social integration, smoking, alcohol consumption, positive affect, negative affect

Social integration (SI) refers to participation in a broad range of social relationships (Brissette, Cohen, \& Seeman, 2000) and is rooted in Durkheim's (1897/1951; Thoits, 1983) seminal work indicating that suicide was most prevalent among those who were neither married nor had close ties with the community and church. There is no accepted or standard measure of integration, but most assess the number of recognized social positions (roles) or identities (e.g., points are assigned for being a spouse, father, friend, or church member). SI has attracted the attention of psychologists interested in the role of interpersonal relationships in health because of its reliable association with both psychological and physical well-being. More than a dozen prospective community-based studies have reported that socially integrated people live longer (see reviews by Berkman \& Glass, 2000; Cohen, 1988, 2004; House, Landis, \& Umberson, 1988; Uchino, 2004); other studies have found that greater integration predicts increased survival from heart attacks (see reviews by Berkman, 1995; Seeman, 1996), less risk for cancer recurrence (see reviews by Helgeson, Fritz, \& Cohen, 1998), less upper respiratory illness (Cohen, Doyle, Skoner, Rabin, \& Gwaltney, 1997), less depression and anxiety (see reviews by Cohen \& Wills, 1985; Kawachi \& Berkman, 2001), and less severe cognitive decline with aging (Bassuk, Glass, \& Berkman, 1999).

Sheldon Cohen, Department of Psychology, Carnegie Mellon University; Edward P. Lemay, Department of Psychology, Yale University.

This research was supported by Grants HL65111 and HL65112 to the Pittsburgh Mind-Body Center from the National Heart, Lung, and Blood Institute and by the John D. and Catherine T. MacArthur Foundation Network on Socioeconomic Status and Health. We are indebted to Ellen Conser, Jeffrey Best, and the volunteers for their contributions to the research.

Correspondence concerning this article should be addressed to Sheldon Cohen, Department of Psychology, Carnegie Mellon University, Pittsburgh, PA 15213. E-mail: scohen@cmu.edu
Despite this sizable descriptive literature linking diverse social networks to morbidity and mortality, there have been virtually no analytic studies to test well-formulated hypotheses about why this occurs. In this study, we examined whether people with more diverse social networks differ on daily affect and rates of smoking and alcohol use, all of which are ultimately relevant for health status. We also tested several models of how SI might influence these outcomes. First, we examined traditional theories that suggest that SI operates by generating dispositional-like characteristics, including feelings of mastery, purpose, and positive affect (PA), that are thought to motivate better health behaviors and regulate affect (see reviews in Cohen, 1988; Thoits, 1983; Uchino, 2004). Second, we tested the proposal that SI is associated with better health because it is a marker of having social support for addressing life adversities (House et al., 1988; Uchino, 2004). In turn, this support is thought to provide protection from stresstriggered increases in smoking, drinking, and negative affect and decreases in PA. Third, we tested the possibility that the SI associations with health are driven by social isolation. Specifically, we examined whether being below some threshold of social contact results in stress and negative affect that, in turn, contribute to higher rates of smoking and drinking and poorer affect regulation (Cacioppo \& Hawkley, 2003; Cohen, 2004; Rook, 1984).

We also proposed the possibility that persons with diverse social networks respond to others differently from those with less diverse networks. This could occur because those higher in SI have higher levels of purpose, mastery, and self-esteem, as suggested earlier, but may also occur because those higher in SI interact with different types of people or because the experiences of interacting with a broad range of others alters how one views one's social world. Specifically, we were interested in how SI might influence affect regulation and the conduct of health-relevant behaviors in social settings. We hypothesized that individuals high in SI are accustomed to interacting with a broad range of people and are consequently less emotionally responsive to being with others. We 
also predicted that the diversity of their networks makes them less subject to social pressures by specific subgroups to drink or smoke. Moreover, because these individuals have a broad range of experiences interacting across social domains, they may be less dependent on alcohol and cigarettes to facilitate social interaction.

Finally, we investigated the role of a number of variables that might provide alternative spurious (third factor) explanations for associations among SI, health behaviors, and affective response. These include social dispositions that have evolved from the traditional personality literature, such as extraversion and agreeableness, as well as other variables representing our ability to form and maintain social networks, such as caring, communal orientation, and tendencies toward negative social interaction (Lakey \& Cohen, 2000; Reis \& Collins, 2000).

In the present study, we monitored participants' interactions, health-related behaviors, and affect for 14 consecutive days. We conducted between-subjects analyses to determine whether SI was associated with PA and negative affect (NA) and with smoking and alcohol consumption. We expected to find SI associated with more PA, less NA, and less smoking and alcohol consumption (Berkman \& Breslow, 1983; Cohen \& Wills, 1985; Uchino, 2004; Umberson, 1987). We also tested whether these relations can be explained by the mechanisms discussed earlier, including mastery, purpose, social support, or psychological stress. Finally, we asked whether SI moderates how people respond (affect, drinking, and smoking) in social situations. We also examined the possibility that any relationship we found might be attributable to SI merely acting as a proxy for the social personality characteristics extraversion and agreeableness or for common measures of interpersonal relationships such as caring and communal orientation.

\section{Method}

The participants were 95 men and 98 women ages 21 to 54 years (mean age $=37.3$ years, $S D=8.8$ ) who responded to newspaper advertisements soliciting participants for studies of psychosocial risk factors for upper respiratory infections. There were 108 White, 72 African American, and 13 other racial/ethnic categories represented in the sample. The mean level of education was 13.76 years $(S D=2.21)$, and median income was $\$ 17,500$, with a range of $\$ 2,500$ to $\$ 162,500$. The sample contained $28.5 \%$ full-time employees, $26.9 \%$ part-time employees, $22.3 \%$ unemployed persons, $15.3 \%$ other nonworking categories (e.g., housewife, retired), and $7.3 \%$ were other unidentified categories. Finally, $47.2 \%$ were smokers, and $65.8 \%$ drank at least one alcoholic drink during the 14 days of monitoring. Here, we report an analysis of baseline data obtained prior to any of the parent study-related interventions. All components of the study received IRB approval, and participants were paid $\$ 820$ for completing all aspects of the parent study.

After a physical exam found them to be in good health (no acute or chronic illnesses), participants filled out the SI measure as well as demographic, personality, social support, mastery, and purpose scales. They were subsequently interviewed on the phone for 14 consecutive evenings to assess their daily interactions, moods, and rates of smoking and alcohol consumption. Approximately 1 week later, they completed the remaining social interaction, stress, and negative affect scales.

\section{Psychological Questionnaires}

SI. The Social Network Index assesses participation in 12 types of social relationships (Cohen et al., 1997). These include relationships with spouse, parents, parents-in-law, children, other close family members, neighbors, friends, workmates, schoolmates, fellow volunteers (e.g., charity or community work), members of groups without religious affiliations (e.g., social, recreational, professional), and members of religious groups. One point was assigned for each kind of relationship for which respondents reported that they spoke (in person or on the phone) to someone in that relationship at least once every 2 weeks. The total possible score was 12 .

Social personality. Extraversion and agreeableness were each measured with shortened (5-item) versions of the subscales from the Goldberg Big Five Questionnaire (Goldberg, 1992; Cohen et al., 1997). Each item is a trait (extraversion: talkative $[+]$, bashful $[-]$, shy $[-]$, extraverted $[+]$, quiet $[-]$; agreeableness: cold $[-]$, rude $[-]$, unkind $[-]$, pleasant $[+]$, harsh $[-]$ ), and respondents indicated how accurately the trait described how they "typically are" on a scale ranging from 0 (not at all accurate) to 4 (extremely accurate). These two scales were each administered twice, approximately 4 weeks apart, and the scores from the two assessments were averaged.

Interpersonal relationships. The 9-item version of the Positive Relationship with Others Scale (Ryff, 1989) assesses caring about others and the ability to have satisfying relationships. An example of an item is "Most people see me as loving and affectionate." The 14-item Communal Orientation Scale (Clark, Ouellette, Powell, \& Milberg, 1987) measures the tendency to view one's relationships as communal (caring for others' needs). The frequency of negative interactions with significant others was assessed by a 5-item scale (Krause, 1995). Examples of questions include "How often have others made too many demands on you?" "How often have others been critical of you?" and "How often have others pried into your affairs?"

Social support. Perceived availability of social support when facing adversity was assessed with a short (12-item) version of the Interpersonal Support Evaluation List (ISEL; Cohen, Mermelstein, Kamarck, \& Hoberman, 1985). The short measure includes equal numbers of questions assessing appraisal, belonging, and selfesteem support.

Mastery. Perceived mastery over important life outcomes was assessed with the 7-item Mastery Scale (Pearlin \& Schooler, 1978).

Purpose. Purpose in life, defined in terms of the extent to which a person engages in activities that are personally valued, was assessed with the 6-item Life Engagement Scale (Scheier et al., 2006).

Negative affect and stress. Psychological stress was assessed by the 10-item Perceived Stress Scale (Cohen, Kamarck, \& Mermelstein, 1983). The scale measures the degree to which situations in life were perceived as stressful during the past month. The Negative Affect scale includes 9 items from the three subscales (depression, anxiety, and anger) from a factor analysis of the Profile of Mood States (Usala \& Hertzog, 1989). Participants reported affect frequency during the past week. Finally, the 5-item version of the emotional instability subscale from the Goldberg Big Five Questionnaire (Goldberg, 1992) requires participants to 
rate how accurately various single-word traits (irritable, nervous, resentful, tense, depressed) describe how they typically are.

For all the scales, the appropriate items were reversed, and the scale scores were summed. The test-retest correlations were .81 for Extraversion and .64 for Agreeableness $(p s<.001)$. The internal reliabilities were .71-.78 for Extraversion, .69-.79 for Agreeableness, .79 for Positive Relationships, .80 for the ISEL, .73 for Communal Orientation, .77 for Negative Interactions, .72 for Mastery, .73 for Life Engagement, .80 for Emotional Instability, .88 for Negative Affect, and .88 for Perceived Stress.

\section{Interviews}

Participants were interviewed on the telephone for 14 consecutive evenings. Interviewers were blind to psychological questionnaires and the hypotheses of this study. Each evening, participants were asked whether they had participated with someone else in each of seven different broadly defined activity categories during the previous $24 \mathrm{hr}$. These included having a meal, drink or dessert, cup of coffee, etc.; leisure activities at home; leisure activities away from home; work around the house; family or personal errands; anything else with anyone, such as visiting, exercising, going to church; and spending at least $15 \mathrm{~min}$ with other(s) in any other activity. For each category they participated in, they were asked exactly what they did and with whom. They could list more than one activity for each category. We calculated the number of people with whom they interacted (within these activities) during each 24-hr period. Individuals were counted only once within any day.

The interviewers also queried how many cigarettes participants had smoked and alcoholic drinks they had consumed during the previous $24 \mathrm{hr}$. A bottle of beer, shot of whiskey, or glass of wine each counted as one drink. A sizable body of public health literature that includes biochemical measures has shown that reports of smoking and alcohol use are quite valid under these conditions (e.g., Patrick et al., 1994; Wills \& Cleary, 1997).

Finally, participants were asked to rate how they felt since they got up that morning using six positive and six negative adjectives (Cohen, Doyle, Turner, Alper, \& Skoner, 2003; from factor analysis by Usala \& Hertzog, 1989). The positive scale contained items assessing vigor (full of pep, lively), calm (at ease, calm), and well-being (cheerful, happy). The negative scale included depression (sad, unhappy), anxiety (on edge, tense), and anger (angry, hostile). These scales have been described as representing activated (anxiety, anger, vigor, and well-being) and unactivated (calm and depression) dimensions of affect (Cohen et al., 2003). Ratings ranged from 0 (haven't felt that way at all today) to 4 (felt that way a lot today). The Cronbach alpha coefficients over the 14 days ranged from .82 to .90 for the positive scale and from .83 to .90 for the negative scale.

\section{Results}

\section{Analytic Strategy}

A series of two-level multilevel models was tested using HLM 5.05 (Raudenbush, Bryk, Cheong, \& Congdon, 2000) to appropriately analyze the current nested data structure (see Bryk \& Raudenbush, 1992; Nezlek, 2001). The 2,674 daily interviews (Level
1) were nested within 191 participants (Level 2). (Two subjects were dropped from the analysis because of missing data.) All within-person (daily) variables were centered on each individual's mean, and their effects were modeled as randomly varying across individuals. Between-persons predictors (i.e., SI) were centered around the sample mean. We examined effects of daily number of interaction partners on same-day outcome variables. Interactions of SI and daily number of interaction partners were decomposed using procedures recommended by Aiken and West (1991). Conditional slopes were estimated by centering SI at low $(-1 S D)$ or high $(+1 S D)$ values and testing the effect of daily interaction partners after replacing SI with one of these transformed variables. Effect sizes (ES) were computed using Rosenthal and Rosnow's (1984) suggested formula, based on $t$ values of fixed effects. Percentage change in ES (mediation analyses) was calculated (ES when mediator was added to the equation - original ES/original $\mathrm{ES})$.

\section{Covariates}

Neither age nor race was associated with SI $(p s>.17)$. However, women $(M=5.68)$ reported greater SI than men $(M=5.11)$, $t(190)=-2.14, p<.05$. Consequently, gender was included as a covariate in all models. All covariates, including individual difference variables described below, were modeled both as main effects and as interactions with all day-level predictors.

Means and variance components. Totally unconditional models (intercepts only) were analyzed to generate means and variance components for each of the daily variables (see Table 1). Substantial Level 1 variance (within-participants, across the day observations) was found for each of the measures, suggesting that participants' values on these measures fluctuated from one day to the next. This suggests the utility of day-level predictors (i.e., number of interaction partners) for modeling daily changes in affect and health behaviors. In addition, the substantial Level 2 variance components indicate individual differences in affect and health behaviors (as averages across all the days), suggesting the utility of individual difference predictors in modeling these averages (i.e., SI).

Main effects of SI (between-participants). Greater SI was associated with interacting with more people $(b=.31$, ES $=.32$, $p<.001)$, consuming fewer alcoholic drinks $(b=-.09$, ES $=.16$, $p<.05)$, and smoking fewer cigarettes $(b=-.50$, ES $=.15, p<$ $.05)$ on an average day over the 14-day period. However, it was not associated with average PA or NA $(p \mathrm{~s}>.16)$.

Main effects of daily number of interaction partners (withinparticipant). The more people with whom participants interacted during a day, the greater their PA $(b=.10, \mathrm{ES}=.16, p<.05)$, alcoholic consumption $(b=.14, \mathrm{ES}=.31, p<.001)$, and number of cigarettes smoked $(b=.11, \mathrm{ES}=.22, p<.01)$ that day. Number of interaction partners was not associated with daily NA, $p=.14$.

\section{Interactions of SI and Number of Daily Interaction Partners}

Health practices. Effects of daily number of interaction partners on alcohol consumption and smoking were moderated by SI (interaction: $b=-.03, \mathrm{ES}=.17, p<.05$, for drinking and $b=$ 
Table 1

Means and Variance Components of Daily Variables

\begin{tabular}{lrcr}
\hline \multicolumn{1}{c}{ Variable } & $M$ & $\begin{array}{c}\text { Within-participant } \\
\text { (Level 1) variance }\end{array}$ & $\begin{array}{c}\text { Between-participants } \\
\text { (Level 2) variance }\end{array}$ \\
\hline Number of interaction partners & 3.43 & 4.25 & 3.66 \\
Positive affect & 14.94 & 12.24 & 15.64 \\
Negative affect & 3.19 & 14.23 & 7.15 \\
Calm & 5.21 & 2.02 & 2.26 \\
Well-being & 5.34 & 1.81 & 1.90 \\
Vigor & 4.39 & 2.32 & .57 \\
Anger & .74 & 2.01 & 1.44 \\
Anxiety & 1.37 & 2.31 & 1.08 \\
Depression & 1.07 & 2.28 & 57.10 \\
Number of cigarettes & 5.49 & 10.63 & 1.48 \\
Number of alcoholic drinks & .90 & 4.11 &
\end{tabular}

-.04 , ES $=.15, p<.05$, for smoking). The effects of number of interaction partners on increased drinking and smoking were greater for people low in SI (drinking: $b=.21, \mathrm{ES}=.27, p<$ .001 ; smoking: $b=.20, \mathrm{ES}=.25, p<.01)$ than for people high in SI (drinking: $b=.08, \mathrm{ES}=.19, p<.01$; smoking: $b=.07$, $\mathrm{ES}=.14, p<.05$; see Figures 1 and 2).

Affect. The effect of daily interaction partners on PA was moderated by SI (interaction was marginal: $b=-.04$, ES $=.13$, $p=.08$ ). Specifically, those high in SI reported high levels of PA irrespective of the number of people with whom they interacted during the day $(p=.58)$; in contrast, those low in SI who interacted with few people during the day had low levels of PA, but as the number of people with whom they interacted increased, their PA increased $(b=.19, \mathrm{ES}=.19, p<.01)$.

Because the interaction with the total PA scale was marginal, we examined each of the subscales separately to see whether the type of PA mattered. The interaction held up for vigor $(b=-.02$, ES $=$ $.15, p<.04)$ and marginally for well-being $(b=-.02, \mathrm{ES}=.13$, $p=.07)$ subscales but did not approach significance for calm $(p=$ .60). The interactions of SI $\times$ Number of Interaction Partners in predicting vigor and well-being are displayed in Figure 3. These patterns of results are similar to what we found when using total PA (all three subscales); number of interaction partners predicted increased well-being $(b=.09, \mathrm{ES}=.23, p=.002)$ and vigor $(b=$ $.09, \mathrm{ES}=.24, p=.001)$ for those low in SI but had no effect for those high in SI $(p s>.27)$. SI did not moderate the effect of daily

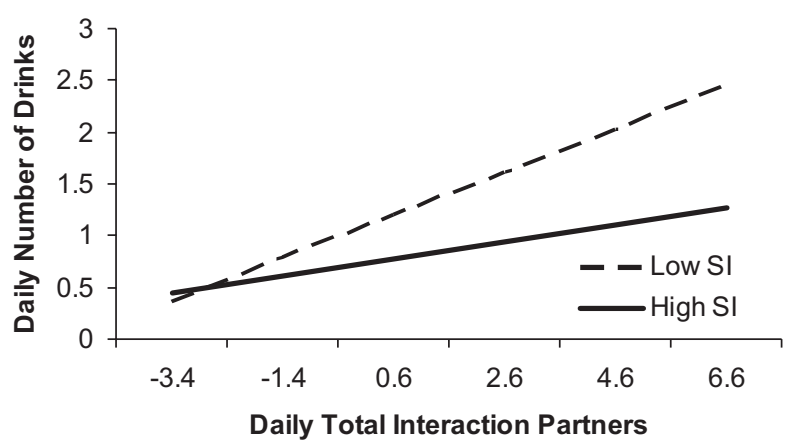

Figure 1. Effect of daily total interaction partners (deviations from participants' average) on concurrent daily number of drinks as a function of individual differences in social integration (SI), controlling for gender. number of interaction partners on daily negative affect $(p=.32)$ or any of the daily negative affect subscales (anxiety, depression, anger; $p s>.23$ ).

\section{Why Do High- and Low-SI People Differ in Their Response to Others?}

$P A$. Could the differences in well-being or vigor explain why low- and high-SI people behave differently in response to an increasing number of people? If PA is the mediator, then entering well-being and vigor and the SI $\times$ Well-Being and SI $\times$ Vigor interactions into the health behavior analyses reported above should substantially reduce the interaction of SI $\times$ Number of Interaction Partners. As apparent from Table 2, these control variables had only a small impact on the interaction predicting smoking (18\% reduction in ES) and resulted in no reduction at all on the interaction predicting drinking ( $2 \%$ increase).

Type of interaction partners. Another possibility is that people who are high in SI have qualitatively different types of interaction partners than do people who are low in SI. We computed the number and percentage of interactions with close (parents, children, close relatives and friends, in-laws, and significant others) and other partners (e.g., nonclose relatives and friends, neighbors, church and social group members, schoolmates, fellow volunteers). SI was associated with having both more close $(b=.22$, $p<.001$; high SI $[+1 S D]$ close $M=2.8$; low SI $[-1 S D]$ close

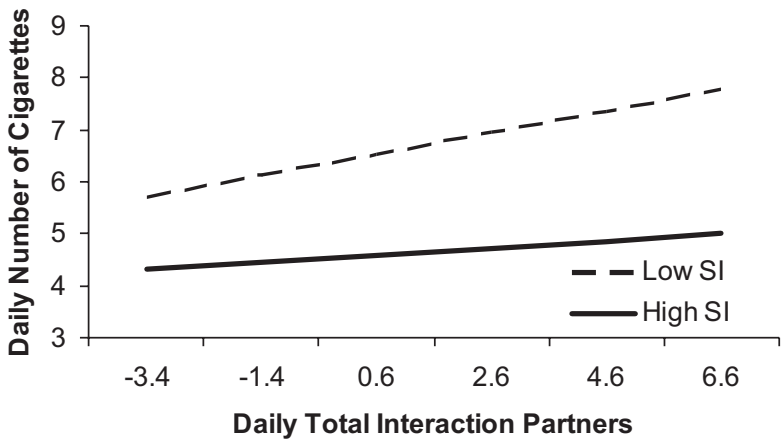

Figure 2. Effect of daily total interaction partners (deviations from participants' average) on concurrent daily number of cigarettes as a function of individual differences in social integration (SI), controlling for gender. 

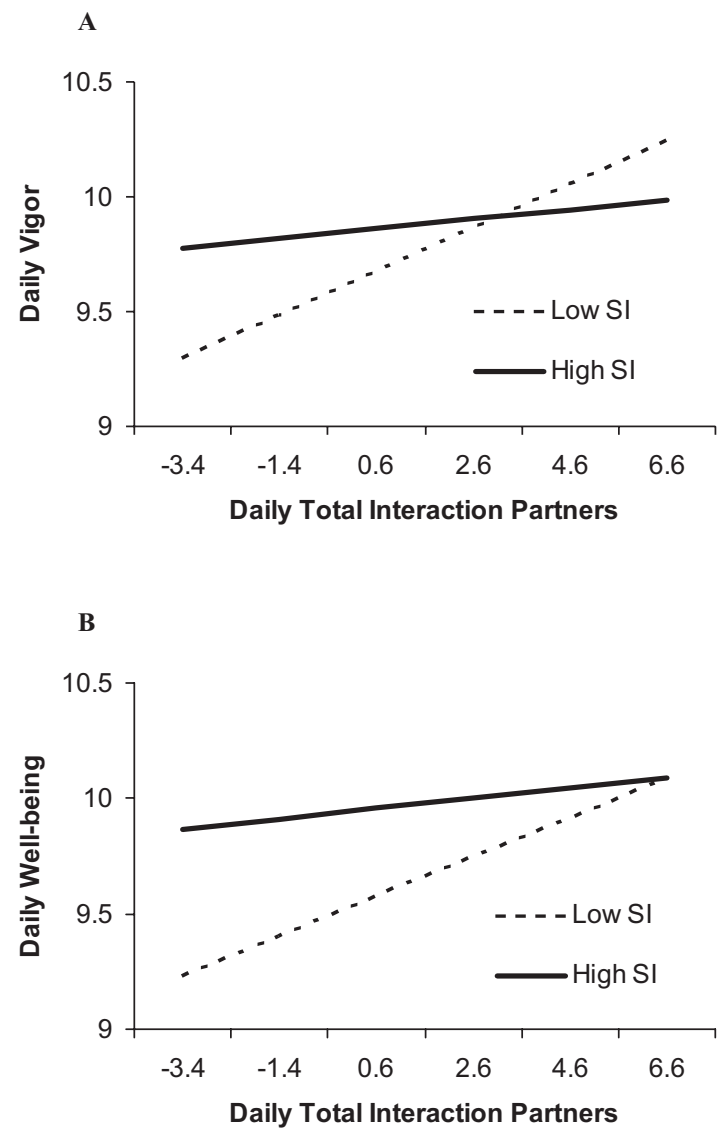

Figure 3. Effect of daily total interaction partners (deviations from participants' average) on concurrent daily positive affect (vigor [A] and well-being $[\mathrm{B}]$ ) as a function of individual differences in social integration (SI), controlling for gender.

$M=1.98)$ and more distant $(b=.09, p<.05$; high SI distant $M=$ 1.2; low SI distant $M=.86$ ) partners. However, the percentage of partners who were close was not correlated with SI $(r=-.05)$. As indicated in Table 2, all of the interactions between SI and number of partners reported earlier were nearly identical (no reductions in effect sizes) after controlling for individual differences in average percentage of partners who were close and the SI $\times$ Percentage of Close Partners interaction.

Health practices. We also conducted an analysis to determine whether changes in drinking and smoking may have been responsible for improvement in mood with increased numbers of interaction partners among participants with high SI. Controlling for daily drinking, daily smoking, and the interactive effects of SI and these variables resulted in minimal reductions in the ES for either concurrent daily vigor or well-being (Table 2).

\section{Is SI Merely a Proxy for Social Personality and Relationship Variables?}

SI was significantly correlated with communal orientation $(r=$ $.19, p<.01)$, negative interactions $(r=.25, p<.001)$, and relationship caring and satisfaction $(r=.28, p<.001)$, but it was not related to extraversion $(r=.05)$ or agreeableness $(r=.13)$.
Adding all of these variables as Level 2 covariates did not substantially influence the main effects of SI (Table 3), with the largest reduction $(25 \%)$ in the association of SI and number of interaction partners. Similarly, adding these covariates and their interaction with SI did not reduce the ES of the SI $\times$ Number of Interaction Partners interactions (Table 2).

\section{Does SI Operate Through Social Support?}

We found only a moderate correlation between the ISEL and SI $(r=.21, p<.05)$. Moreover, adding ISEL as a Level 2 covariate had little impact on the main effects of SI (Table 3), and adding ISEL and the SI $\times$ ISEL interaction had little effect on the interaction of SI with number of interaction partners (Table 2).

\section{Does SI Operate Through Mastery or Purpose?}

SI was correlated with mastery $(r=.20, p<.01)$ and purpose $(r=.27, p<.001)$. In analyses controlling for both of these variables, main effects of SI on daily interaction partners and drinking were only marginally reduced (Table 3), but the main effect of SI on smoking was reduced substantially by the inclusion of mastery and purpose (39\% effect reduction). Instead, purpose predicted reduced smoking $(b=-.35, p=.056)$. In contrast, none of the interactions of SI with daily number of interaction partners was substantially reduced by the inclusion of mastery and purpose and their interactions with SI (Table 2).

\section{Does SI Operate Through Stress and Negative Affect?}

SI was correlated with perceived stress $(r=-.21, p<.01)$ and emotional instability $(r=-.13, p=.08)$ but was not significantly correlated with averaged negative affect across the 14 interview days $(p=.69)$ or retrospective reports of negative affect $(p=$ .53). Adding all four variables as Level 2 covariates did not substantially influence the main effects of SI (Table 3). Similarly, these covariates and their interactions with SI did not at all reduce the SI $\times$ Number of Interaction Partners interactions predicting health outcomes (Table 2).

\section{Analyses of Smokers and of Drinkers}

To rule out the possibility that the lack of within-participant variance for nonsmokers and nondrinkers may have biased our conclusions, additional analyses of smoking and drinking restricted the sample only to smokers $(n=103)$ and drinkers $(n=$ 127). Smoking was defined as indicating smoking cigarettes on at least 1 day during the 14 days of interviews and drinking as indicating having an alcoholic beverage on at least 1 of those days. These analyses produced virtually identical results to those involving the whole sample.

\section{Considering E-mail Contact in SI}

Studies on SI and health have traditionally assessed face-to-face contacts or phone contacts. Because a major purpose of this study was to explain associations reported in those studies, we did the same in the primary analyses. However, we also asked participants whether they had e-mail contacts at least once every 2 weeks with people in each social role, and we calculated a revised SI measure 
Table 2

Changes in Effect Sizes of the Interactions Between Social Integration and Daily Number of Interaction Partners When Covariates Are Added to the Equation

\begin{tabular}{|c|c|c|c|c|c|c|c|c|c|c|c|c|}
\hline \multirow[b]{2}{*}{ Covariate } & \multicolumn{3}{|c|}{ Daily well-being } & \multicolumn{3}{|c|}{ Daily vigor } & \multicolumn{3}{|c|}{$\begin{array}{c}\text { Daily number of alcoholic } \\
\text { drinks }\end{array}$} & \multicolumn{3}{|c|}{$\begin{array}{l}\text { Daily number of } \\
\text { cigarettes }\end{array}$} \\
\hline & $b$ & ES & $\begin{array}{l}\% \text { ES } \\
\text { change }\end{array}$ & $b$ & ES & $\begin{array}{l}\% \text { ES } \\
\text { change }\end{array}$ & $b$ & ES & $\begin{array}{l}\% \text { ES } \\
\text { change }\end{array}$ & $b$ & ES & $\begin{array}{l}\% \text { ES } \\
\text { change }\end{array}$ \\
\hline None (gender only) & $-.02^{\dagger}$ & .13 & - & $-.02^{*}$ & .15 & - & $-.03^{*}$ & .17 & - & $-.04^{*}$ & .15 & - \\
\hline PA & - & - & - & - & - & - & $-.03^{*}$ & .17 & +2 & $-.03^{\dagger}$ & .13 & -18 \\
\hline Percentage of close partners & $-.02^{\dagger}$ & .13 & 0 & $-.02^{*}$ & .15 & 0 & $-.03^{*}$ & .17 & +2 & $-.04^{*}$ & .16 & +2 \\
\hline Health practices & -.01 & .12 & -11 & $-.02^{*}$ & .15 & +1 & - & - & - & - & - & - \\
\hline Social personality & $-.02^{*}$ & .15 & +18 & $-.03^{*}$ & .16 & +10 & $-.03^{*}$ & .17 & -1 & $-.04^{*}$ & .15 & 0 \\
\hline Social support & $-.02^{*}$ & .14 & +6 & $-.02^{*}$ & .15 & +2 & $-.04^{* *}$ & .19 & +14 & $-.04^{*}$ & .15 & +1 \\
\hline Mastery and purpose & $-.02^{\dagger}$ & .12 & -8 & $-.02^{\dagger}$ & .13 & -12 & $-.03^{*}$ & .17 & +2 & $-.04^{*}$ & .16 & +4 \\
\hline Stress and negative affect & $-.02^{*}$ & .14 & +8 & $-.02^{*}$ & .15 & +3 & $-.04^{*}$ & .18 & +9 & $-.04^{*}$ & .16 & +4 \\
\hline All covariates & $-.02^{\dagger}$ & .14 & +6 & $-.02^{\dagger}$ & .14 & -7 & $-.03^{*}$ & .17 & +2 & $-.03^{*}$ & .16 & +4 \\
\hline
\end{tabular}

Note. All models controlled for gender. Individual difference covariates were modeled as main effects on daily outcomes and as moderators of all day-level predictors. $\mathrm{ES}=$ effect size; $\mathrm{PA}=$ positive affect.

${ }^{*} p<.05 .{ }^{* * *} p<.01 . \dagger p<.10$.

that took these into account. (Only $43 \%$ of our participants used e-mail.) The score on the revised scale was correlated $(r=.96$, $p<.001)$ with the original score. Moreover, analyses using the revised score resulted in virtually identical results.

\section{Discussion}

As expected, the greater the SI score, the more people participants joined with in activities on the average day. Those high in SI interacted with more people in their family and close circle, as well as with more people in distant relationships, such as fellow workers, students, and volunteers. These data support the view that SI taps diversity of participation in a broad social network.

Higher SI scores were also associated with consuming fewer alcoholic drinks and smoking fewer cigarettes (cf. Berkman \& Breslow, 1983). Our evidence does not, however, support hypotheses that attribute these associations to SI relations with positive or negative affect. Nor does it support the hypothesis that SI associations with health practices are mediated by greater perceptions of social support or mastery. In contrast, SI associated with purpose in life may play some role at least in relation to smoking. Probably a more potent source of mediation (although not directly tested here) is that SI is associated with social pressure by the network to stay healthy and by greater responsibility of socially integrated people to others (Cohen, 1988, 2004; Uchino, 2004; Umberson, 1987). Given that the focus here was on health practices, social influences were potential mechanisms at the forefront. It is still possible that other expected mediators of health outcomes, such as changes in endocrine or cardiovascular levels, could be driven by the cognitive and affective pathways that did not play a role in mediating the health behavior outcomes.

As we have discussed, increases in SI were associated with less smoking and alcohol consumption. One might similarly expect that interacting with more people would be a positive indicator of social and psychological well-being. In fact, the within-participant analyses indicated that increases in the number of people interacted with during a day were associated with increases in PA on the same day. Paradoxically, more interaction partners during a day was also associated with increases in smoking and alcohol

Table 3

Changes in Effect Sizes of Main Effects of Social Integration on Daily Outcome Variables When Covariates Are Added to the Equation

\begin{tabular}{|c|c|c|c|c|c|c|c|c|c|}
\hline \multirow[b]{2}{*}{ Covariates } & \multicolumn{3}{|c|}{$\begin{array}{l}\text { Daily number of } \\
\text { interaction partners }\end{array}$} & \multicolumn{3}{|c|}{$\begin{array}{l}\text { Daily number of } \\
\text { alcoholic drinks }\end{array}$} & \multicolumn{3}{|c|}{$\begin{array}{l}\text { Daily number of } \\
\text { cigarettes }\end{array}$} \\
\hline & $b$ & ES & $\begin{array}{l}\% \text { ES } \\
\text { change }\end{array}$ & $b$ & ES & $\begin{array}{l}\% \text { ES } \\
\text { change }\end{array}$ & $b$ & ES & $\begin{array}{l}\% \text { ES } \\
\text { change }\end{array}$ \\
\hline None (gender only) & $.31^{* * *}$ & .32 & - & $-.09^{*}$ & .16 & - & $-.50^{*}$ & .15 & - \\
\hline Social personality & $.24^{* *}$ & .24 & -25 & $-.08^{\dagger}$ & .14 & -11 & $-.40^{\dagger}$ & .12 & -19 \\
\hline Social support & $.27^{* * *}$ & .27 & -16 & $-.12^{* *}$ & .20 & +28 & $-.53^{*}$ & .16 & +7 \\
\hline Mastery and purpose & $.27^{* * *}$ & .27 & -14 & $-.09^{*}$ & .16 & -1 & -.33 & .09 & -39 \\
\hline Stress and negative affect & $.29^{* * *}$ & .28 & -12 & $-.10^{*}$ & .18 & +18 & $-.45^{\dagger}$ & .13 & -17 \\
\hline All covariates & $.23^{* *}$ & .22 & -30 & $-.09^{*}$ & .18 & +13 & -.30 & .08 & -46 \\
\hline
\end{tabular}

Note. All models controlled for gender. ES = effect size

${ }^{*} p<.05 .{ }^{* *} p<.01 .{ }^{* * *} p<.001 .^{\dagger} p<.10$. 
consumption on that day. These effects may be attributable to the role that alcohol and cigarettes play in facilitating social interactions (Mohr et al., 2001). It is also possible that more interactants increase participant participation in these behaviors through traditional means of social influence. Finally, persons low in SI might find interacting with others stressful and, therefore, use smoking and drinking as coping strategies (Shiffman \& Wills, 1985), although the failure of smoking or drinking to mediate effects of interaction partners on PA suggests that, if this were the mechanism, it is not very effective.

Unique to this article was the proposal that SI might influence how people react to their social environment. In fact, it was primarily the low-SI people whose PA, smoking, and drinking increased with the number of people with whom they interacted. In contrast, PA, smoking, and alcohol consumption of those higher in SI were relatively independent of the number of interaction partners. This result is consistent with the argument that higher SI people are responsive to the ongoing normative constraints to live a healthy lifestyle that belonging to an integrated social network places on them. In contrast, the less integrated may be more susceptible to moment-by-moment social pressures that influence their smoking and drinking behaviors. Differences in SI are not associated with the proportion of interactants with whom they have close relationships, but it is possible that people lower in SI are more likely to interact with others who drink and smoke and, hence, more people may represent more negative social pressure.

It is interesting that when we broke PA into the three subscales, it was feelings such as full of pep, cheerful, and happy ("activated" PA) that were associated with more social interaction in those with low SI. Unactivated affects (e.g., ease and calm) were not. This suggests a somewhat different perspective than the generally held position that increased social interaction is associated with increases in "undifferentiated" PA.

Finally, drinking and smoking in the presence of others might be responsible for the association between more interactants and greater PA in persons with low SI. However, this turned out not to be the case. More interaction partners were associated with higher PA irrespective of drinking and smoking rates. Thus, it is something about the interaction itself that is associated with PA, not the drugs.

None of the effects we have reported could be explained by common interpersonal relationship measures (communal orientation, the ability to have caring and satisfying relationships, negative interactions) or by social personality measures (extraversion and agreeableness), suggesting a unique role of humans' network structure in how people react to others. Similarly, with the exception of the role of purpose in smoking, the psychological mediators tested here (mastery, social support, affect) did not play important roles in explaining the associations we found. Nevertheless, it is possible that SI associations with health behaviors are mediated by feelings of loneliness, a potential mediator that was not assessed here (Cacioppo \& Hawkley, 2003). However, smoking and drinking were not mediated by more global measures of NA or perceived stress that are highly correlated with loneliness and are thought to mediate its effects on health (Pressman et al., 2005). Moreover, social isolation is often not strongly associated (sometimes not at all) with loneliness, nor is it considered a sufficient or necessary cause of loneliness (Peplau \& Perlman, 1982; Pressman et al., 2005).
This study does have limitations. Because the analyses were concurrent, causal inferences are not possible. We cannot be sure of the extent to which the health behaviors and affect influenced number of interactants, or whether number of interactants influenced the health behaviors. It seems reasonable, however, that in the case of health behaviors, it was probably the number of people that triggered the behaviors rather than vice versa. In the case of PA, either direction seems quite plausible. It is also possible that unspecified third (spurious) factors were responsible for changes in both variables, although we did account for the potential spurious effects of the most obvious alternatives, including age, gender, race, and an array of social and psychological variables.

\section{References}

Aiken, L. S., \& West, S. G. (1991). Multiple regression: Testing and interpreting interactions. New York: Sage.

Bassuk, S. S., Glass, T. A., \& Berkman, L. F. (1999). Social disengagement and incident cognitive decline in community-dwelling elderly persons. Annals of Internal Medicine, 131, 165-173.

Berkman, L. F. (1995). The role of social relations in health promotion. Psychosomatic Medicine, 57, 245-254

Berkman, L. F., \& Breslow, L. (1983). Health and ways of living: The Alameda County Study. New York: Oxford University Press.

Berkman, L. F., \& Glass, T. (2000). Social integration, social networks, social support, and health. In L. F. Berkman \& I. Kawachi (Eds.), Social epidemiology (pp. 137-173). New York: Oxford University Press.

Brissette, I., Cohen, S., \& Seeman, T. E. (2000). Measuring social integration and social networks. In S. Cohen, L. G. Underwood, \& B. H. Gottlieb (Eds.), Social support measurement and intervention: A guide for health and social scientists (pp. 53-85). New York: Oxford University Press.

Bryk, A. S., \& Raudenbush, S. W. (1992). Hierarchical linear models. Newbury Park, CA: Sage.

Cacioppo, J. T., \& Hawkley, L. C. (2003). Social isolation and health, with an emphasis on underlying mechanisms. Perspectives in Biology and Medicine, 46, S39-S52.

Clark, M. S., Ouellette, R., Powell, M. C., \& Milberg, S. (1987). Recipient's mood, relationship type, and helping. Journal of Personality and Social Psychology, 53, 94-103.

Cohen, S. (1988). Psychosocial models of social support in the etiology of physical disease. Health Psychology, 7, 269-297.

Cohen, S. (2004). Social relationships and health. American Psychologist, 59, 676-684

Cohen, S., Doyle, W. J., Skoner, D. P., Rabin, B. S., \& Gwaltney, J. M., Jr. (1997). Social ties and susceptibility to the common cold. Journal of the American Medical Association, 277, 1940-1944.

Cohen, S., Doyle, W. J., Turner, R. B., Alper, C. M., \& Skoner, D. P. (2003). Emotional style and susceptibility to the common cold. Psychosomatic Medicine, 65, 652-657.

Cohen, S., Kamarck, T., \& Mermelstein, R. (1983). A global measure of perceived stress. Journal of Health and Social Behavior, 24, 385-396.

Cohen, S., Mermelstein, R., Kamarck, T., \& Hoberman, H. (1985). Measuring the functional components of social support. In I. G. Sarason \& B. R. Sarason (Eds.), Social support: Theory, research and application (pp. 73-94). The Hague, Holland: Martinus Nijhoff.

Cohen, S., \& Wills, T. A. (1985). Stress, social support and the buffering hypothesis. Psychological Bulletin, 98, 310-357.

Durkheim, E. (1951). Suicide. New York: Free Press. (Original work published 1897)

Goldberg, L. R. (1992). The development of markers for the Big-Five factor structure. Psychological Assessment, 4, 26-42.

Helgeson, V. S., Fritz, H. L., \& Cohen, S. (1998). Social ties and cancer. 
In J. C. Holland \& W. Breitbart (Eds.), Psycho-oncology (pp. 99-109). New York: Oxford University Press.

House, J. S., Landis, K. R., \& Umberson, D. (1988). Social relationships and health. Science, 241, 540-554.

Kawachi, I., \& Berkman, L. F. (2001). Social ties and mental health. Journal of Urban Health: Bulletin of the New York Academy of Medicine, 78, 458-467.

Krause, N. (1995). Negative interaction and satisfaction with social support among older adults. Journal of Gerontology: Psychological Sciences, $50 B, 59-73$.

Lakey, B., \& Cohen, S. (2000). Social support theory and measurement. In S. Cohen, L. G. Underwood, \& B. Gottlieb (Eds.), Measuring and intervening in social support (pp. 29-52). New York: Oxford University Press.

Mohr, C. D., Armeli, S., Tennen, H., Carney, M. A., Affleck, G., \& Hromi, A. (2001). Daily interpersonal experiences, context, and alcohol consumption: Crying in your beer and toasting good times? Journal of Personality and Social Psychology, 80, 489-500.

Nezlek, J. B. (2001). Multilevel random coefficient analyses of event and interval contingent data in social and personality psychology research. Personality and Social Psychology Bulletin, 27, 771-785.

Patrick, D. L., Cheadle, A., Thompson, D. C., Diehr, P., Koepsell, T., \& Kinne, S. (1994). The validity of self-reported smoking: A review and meta-analysis. American Journal of Public Health, 84, 1086-1093.

Pearlin, L. I., \& Schooler, C. (1978). The structure of coping. Journal of Health and Social Behavior, 19, 2-21.

Peplau, L. A., \& Perlman, D. (1982). Perspectives on loneliness. In L. A. Peplau \& D. Perlman (Eds.), Loneliness: A sourcebook of current theory, research and therapy (pp. 1-20). New York: Wiley.

Pressman, S., Cohen, S., Miller, G. E., Rabin, B. S., Barkin, A., \& Treanor, J. (2005). Loneliness, social network size, and immune response to influenza vaccination in college freshmen. Health Psychology, 24, 297306

Raudenbush, S. W., Bryk, A. S., Cheong, Y. F., \& Congdon, R. T., Jr. (2000). HLM 5: Hierarchical linear and nonlinear modeling. Lincolnwood, IL: Scientific Software International.
Reis, H. T., \& Collins, N. (2000). Measuring relationship properties and interactions relevant to social support. In S. Cohen, L. G. Underwood, \& B. H. Gottlieb (Eds.), Social support measurement and intervention: A guide for health and social scientists (pp. 136-192). New York: Oxford University Press.

Rook, K. S. (1984). The negative side of social interaction: Impact on psychological well-being. Journal of Personality and Social Psychology, 46, 1097-1108

Rosenthal, R., \& Rosnow, R. L. (1984). Essentials of behavioral research: Methods and data analysis. New York: McGraw-Hill.

Ryff, C. D. (1989). Happiness is everything, or is it? Explorations on the meaning of psychological well-being. Journal of Personality and Social Psychology, 57, 1069-1081.

Scheier, M. F., Wrosch, C., Cohen, S., Martire, L. M., Matthews, K. A., Schulz, R., \& Zdaniuk, B. (2006). The Life Engagement Test: Assessing purpose in life. Journal of Behavioral Medicine, 29, 291-298.

Seeman, T. E. (1996). Social ties and health: The benefits of social integration. Annals of Epidemiology, 6, 442-451.

Shiffman, S., \& Wills, T. A. (1985). Coping and substance use. New York: Academic Press.

Thoits, P. A. (1983). Multiple identities and psychological well-being: A reformulation and test of the social isolation hypothesis. American Sociological Review, 48, 416-423.

Uchino, B. N. (2004). Social support and physical health. New Haven, CT: Yale University Press.

Umberson, D. (1987). Family status and health behaviors: Social control as a dimension of social integration. Journal of Health and Social Behavior, 28, 306-319.

Usala, P. D., \& Hertzog, C. (1989). Measurement of affective states in adults: Evaluation of an adjective scale instrument. Research in Aging, $11,403-426$.

Wills, T. A., \& Cleary, S. D. (1997). The validity of self-reports of smoking: Analyses by race/ethnicity in a school sample of urban adolescents. American Journal of Public Health, 87, 56-61. 